\title{
Disección aórtica
}

\section{Aortic dissection}

\author{
Jorge Ignacio Magaña Reyes, ${ }^{*}$ Francisco Sánchez Lezama ${ }^{\ddagger}$
}

Paciente femenino de 69 años, hipertensa de 10 años de evolución; acudió a urgencias por crisis hipertensiva (260/100), 48 horas previas. Durante su hospitalización se agregó dolor torácico retroesternal de moderada intensidad, con irradiación a la región laterocervical derecha.

Se controló la crisis hipertensiva y se realizó angiotomografía en equipo multidetector de 64 canales (GE Medical System, Milwaukee, Wisconsin); ésta mostró: a) disección aórtica desde la unión sinotubular tipo A de Stanford y/o DeBakey tipo II; b) hematoma intramural en el tronco braquiocefálico que condiciona estenosis significativa $\geq$ $70 \%$; c) dilatación de la aorta ascendente $44 \times 45 \mathrm{~mm}$ desde la raíz; d) involucramiento de los orígenes de los troncos supraaórticos (Figuras 1 y 2); e) válvula aórtica trivalva con insuficiencia; $f$ ) estenosis significativa entre los segmentos proximal y medio de la coronaria derecha y g) enfermedad ateromatosa de arterias coronarias. Se solicitó la valoración urgente por el departamento de Cirugía Cardiotorácica.
La disección aórtica (DA) ocurre con mayor frecuencia en pacientes entre la quinta y séptima década de la vida, que tienen historia de hipertensión arterial y arterioesclerosis generalizada; además, la disección aórtica es tres veces más frecuente en el sexo masculino. Los pacientes que no tienen hipertensión pueden asociarse con los síndromes de Marfan, Ehlers-Danlos, Noonan o Turner. Existen causas iatrogénicas como cateterización aórtica y colocación del balón de contrapulsación. Las complicaciones vasculares periféricas se producen cuando el proceso de disección disminuye el flujo de ellas; el mecanismo más frecuente es la compresión de la luz verdadera por la falsa y, con menor frecuencia, ocurre por la obstrucción de la salida del vaso por el flap de la capa íntima.

La insuficiencia aórtica se puede originar por disección retrógrada o secundaria a la dilatación de la raíz aórtica. ${ }^{1}$ La mortalidad de la DA sin tratamiento es muy alta; según la mayoría de los autores, más de un tercio de los pacientes
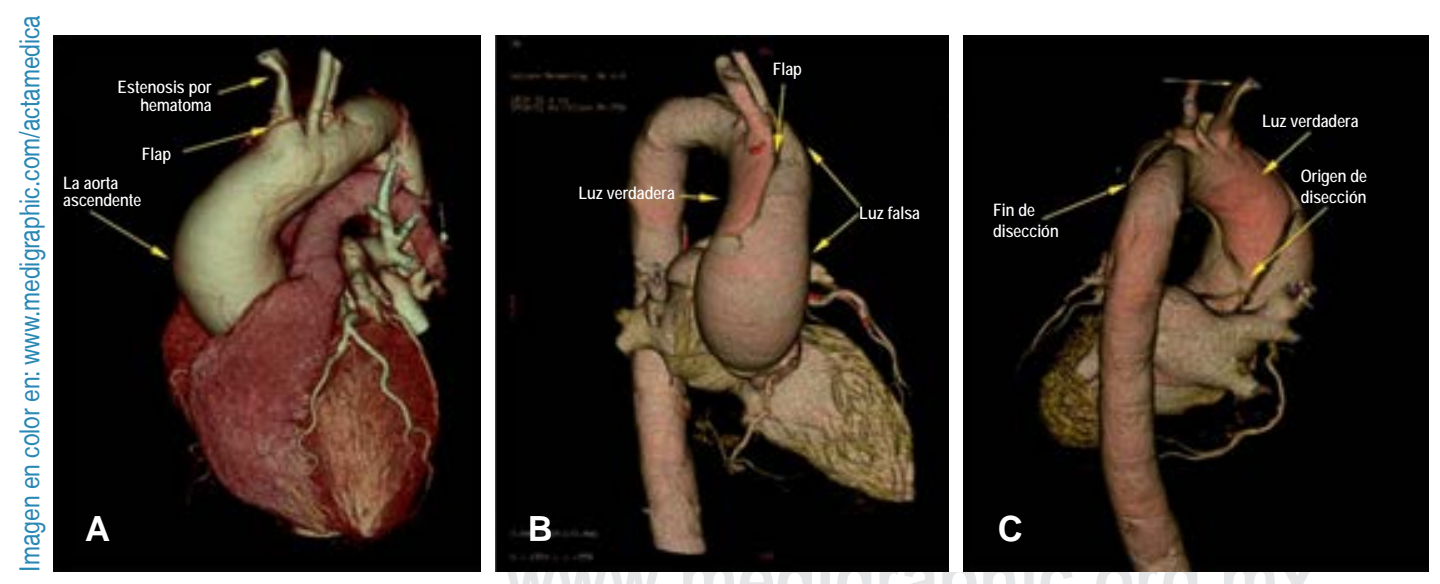

Figura 1.

* Radiólogo. Departamento de Imagenología.
* Cardiólogo. Jefe de Ecocardiografía.

Hospital Ángeles León, León, Guanajuato México.
Correspondencia:

Dr. Jorge Ignacio Magaña Reyes

Correo electrónico: dr.jorgemaganar@gmail.com

Aceptado: 16-05-2019.

www.medigraphic.com/actamedica 

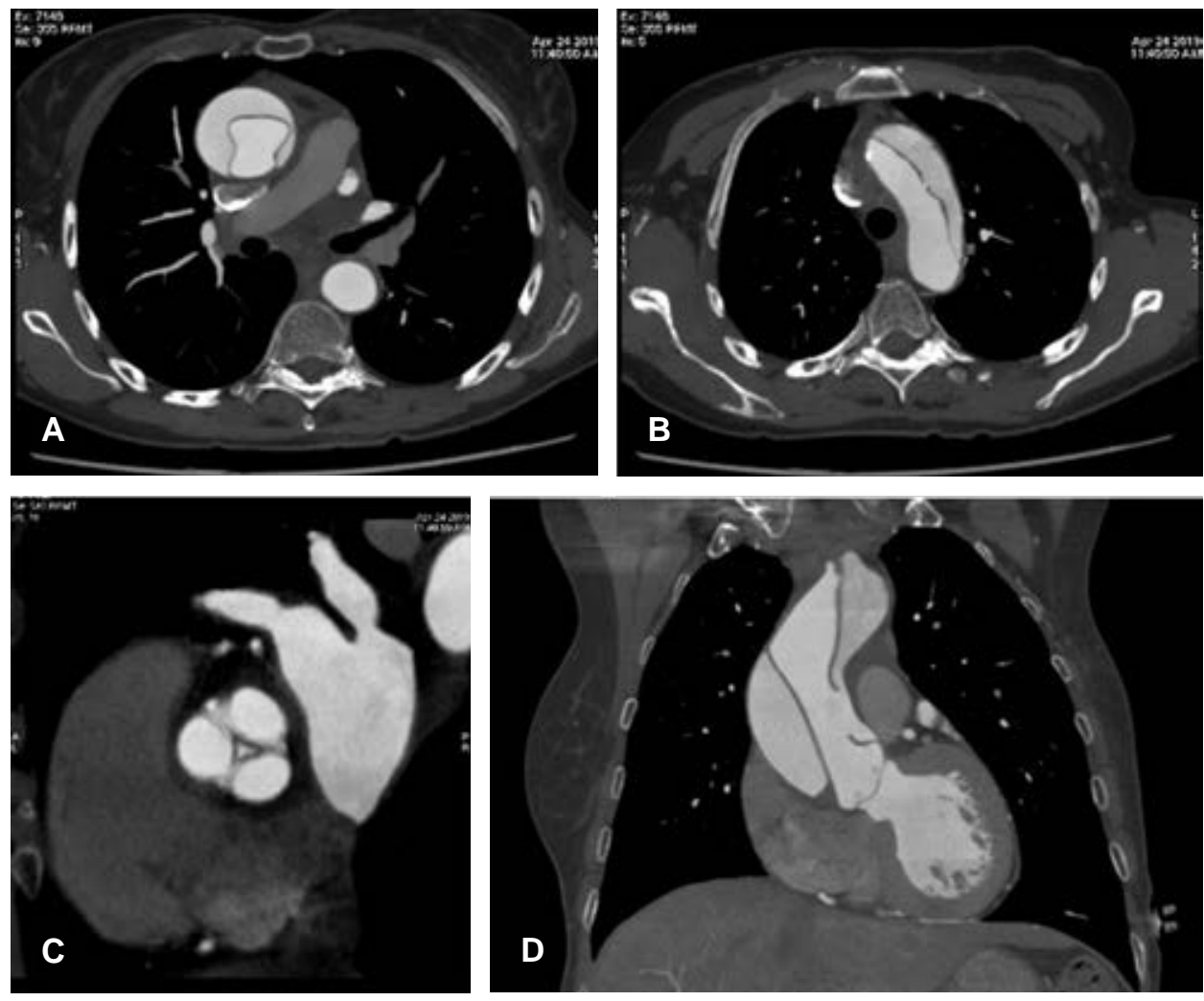

Figura 2.

mueren en las primeras 24 horas, la mitad en las siguientes 48 horas, dos tercios en la primera semana y casi el $90 \%$ muere en el primer mes. ${ }^{2}$ Se requiere reemplazo quirúrgico urgente de la aorta ascendente, con derivaciones a los vasos supraaórticos y reemplazo valvular. ${ }^{3,4}$

\section{REFERENCIAS}

1. Evangelista A, Isselbacher EM, Bossone E, Gleason TG, Eusanio $M D$, Sechtem $U$ et al. IRAD Investigators Insights from the international registry of acute aortic dissection: a 20-year experience of collaborative clinical research. Circulation. 2018; 137: 1846-1860.

2. Froehlich W, Tolenaar JL, Harris KM, Strauss C, Sundt TM, Tsai TT et al. Delay from diagnosis to surgery in transferred type a aortic dissection. Am J Med. 2018; 13 (3): 300-306.

3. Rosenblum JM, Leshnower BG, Moon RC, Lasanajak Y, Binongo J, McPherson L, Chen EP. Durability and safety of David V valve-sparing root replacement in acute type A aortic dissection. J Thorac Cardiovasc Surg. 2019; 157 (1): 14-23.

4. Waterford SD, Gardner RL, Moon MR. Extent of aortic replacement in type A dissection: current answers for an endless debate. Ann Thoracic Surg. 2018; 106 (4): 1246-1250. 